\title{
Impact of nanomaterials on plants: What other implications do they have?
}

\author{
ANTONIO JUÁREZ-MALDONADO* \\ Departamento de Botánica, Universidad Autónoma Agraria Antonio Narro, Saltillo, 25315, México
}

Key words: Nanotechnology, Antioxidant defense system, Secondary metabolites, Ecosystems and the environment

\begin{abstract}
The use of nanomaterials has spread and has been applied in different industries, including agriculture. Here, the possibilities presented by NMs are very varied, from the biostimulation of favorable responses, or the control of pests and diseases, to the monitoring of characteristics of interest with the use of nanosensors. Particularly the biostimulation of agricultural crops with the use of nanomaterials is very relevant, since from this process stress tolerance, higher content of biocompounds, etc., can be induced. Although the positive impacts on crops are clear, there is not enough information to determine the long-term impacts, both on ecosystems and on human health.
\end{abstract}

Nowadays, research has intensified on the use of nanomaterials (NMs) in various areas of agriculture, from their application as nano-fertilizers to their application as nanosensors (Moulick et al., 2020; Singh et al., 2021). This has been thanks to the new characteristics that NMs present, mainly due to the surface/volume ratio, but they also have other properties that directly impact on the interaction that occurs with plant cells, among these are surface charge, surface energy, size, shape, roughness, porosity, hydrophobicity, and hydrophilicity (Das et al., 2019; Juárez-Maldonado et al., 2019). Derived from all these characteristics, a range of different responses can be obtained in plants exposed to NMs (Juárez-Maldonado et al., 2021). One of the main approaches that have been given to the use of NMs in agriculture is their application in order to modify the metabolism and physiology of plants. This results in the increase of multiple characteristics of interest such as crop yield, greater tolerance to some type of stress, greater accumulation of bioactive compounds or secondary metabolites, among others (Awasthi et al., 2020; Kumar et al., 2019; Rizwan et al., 2017).

Due to this, it has been proposed to consider NMs as biostimulants in plants (Juárez-Maldonado et al., 2021, 2019), but also their function as elicitors of secondary metabolites has been proposed (Lala, 2021; Rivero-Montejo et al., 2021). In both cases there is sufficient evidence in the literature to support these claims. However, perhaps the most relevant

*Address correspondence to: Antonio Juárez-Maldonado, antonio.juarez@uaaan.edu.mx

Received: 04 May 2021; Accepted: 16 June 2021 thing is to understand the mechanism of action of NMs that induces the responses observed in different plant species.

It is clear that NMs can enter plants through different routes. However, the route of application can directly influence the final bioaccumulation that can be observed in the plant because NMs, depending on their nature, can be transformed by chemical, physical, biological and macromolecular interactions. The result of these interactions can be agglomeration (NMs that interact with the environment), dissolution (NMs based on metals) or chemical transformation that can be by oxidation or reduction (NMs that interact with the environment or by bioaccumulation) (Petersen et al., 2019). Possibly, once NMs enter plants and interact with cells, organelles and other cellular components, a chemical transformation takes place.

By foliar route they can enter through the stomata or through the cuticle, while through the root they can enter through existing channels, aquaporins, endocytosis, or induce the formation of new pores and afterwards move through the symplast or apoplast until reaching to vascular bundles (Corredor et al., 2009; Pérez-de-Luque, 2017; Tripathi et al., 2017). Once the NMs are in the vascular bundles they can move to the rest of the plant structures (He et al., 2021; Jordan et al., 2018). From the first contact of the NMs with the plant cells, there is an interaction at the physical-chemical level and therefore a series of responses are generated (Juárez-Maldonado et al., 2019). After entering the interior of the cell, there is a new interaction between the NMs and the different cellular organelles, including the nucleus (Ahmed et al., 2021). It is here where a series of changes in cellular metabolism are 
actually induced, among which is the modification of the antioxidant defense system (Khodakovskaya et al., 2012; Yan et al., 2013). The interaction of NMs with membranes or other cellular organelles can trigger the production of reactive oxygen species (ROS), which results in oxidative stress (Tripathi et al., 2017). However, ROS induction is dependent on the type of NMs applied, and furthermore the degree of oxidative stress is dependent on the concentration (Juárez-Maldonado et al., 2021). This characteristic of NMs is quite relevant, since ROS at this point function as signals that activate the antioxidant defense system, resulting in the production of enzymatic (superoxide dismutase, catalase, ascorbate peroxidase, glutathione peroxidase) and nonenzymatic (ascorbic acid, glutathione, phenols) antioxidant compounds (Mittler, 2017). Furthermore, ROS can also influence the different metabolic pathways, and even directly on the expression of genes related to these metabolic pathways (Marslin et al., 2017; Nazir et al., 2019).

The overproduction of antioxidant compounds has multiple repercussions for the plant, since it is necessary to allocate energy for the synthesis of these compounds without causing irreparable damage to the plant itself. Basically, there must be a balance between the harvesting of energy by photosynthesis and the expenditure on the different metabolic and physiological processes, such as respiration, growth, and secondary metabolism (JuárezMaldonado et al., 2021).

The biostimulation capacity of NMs in plants can be used for different purposes, such as those previously mentioned. However, considering the antioxidant system and secondary metabolism, the most relevant for the development of crops is the induction of tolerance to a variety of types of both biotic and abiotic stress (Azizi-Lalabadi et al., 2020; Zhou et al., 2021; Zulfiqar and Ashraf, 2021). This is extremely relevant due to the increasingly difficult situation that exists worldwide for the production of agricultural crops, since climate change brings with it repercussions due to the extreme climates that occur. In addition, the lesser availability of soil suitable for the development of crops and the availability of water, due to problems such as erosion, salinity, or contamination by heavy metals (Machado and Serralheiro, 2017; Ruíz-Huerta et al., 2017).

But also, if it is considered that human health depends largely on the intake of foods rich in biocompounds such as vitamin C, lycopene, phenols, carotenoids, due to its high antioxidant activity that reduces the risk of noncommunicable diseases such as cancer and cardiovascular problems (Cisternas-Jamet et al., 2020; Cortés-Estrada et al., 2020). So, the use of NMs in agriculture represents perhaps an unprecedented opportunity, which will allow us to improve not only the productivity of agricultural crops, but also the quality of the food we consume. However, one must be very careful with the application of the NMs, Amini et al. (2014) suggest adequately studying the exposure routes in industry workers and especially consumers of food products treated with NMs, since a greater and better understanding of the properties of NMs is required to obtain safe food products. Some studies have shown harmful effects in animal species. Amiri et al. (2018) conclude that prenatal exposure to $\mathrm{Ag}$ NPs $\left(0.26 \mathrm{mg} \mathrm{kg}{ }^{-1} \mathrm{day}^{-1}\right)$ can affect the brain and behavior in adult male mice, and suggest further studies to understand the mechanism by which this happens. In contrast, Se NPs can induce beneficial effects because selenium is part of selenoproteins and selenoenzymes resulting in an increase, with the great advantage that Se NPs are less toxic than other organic or inorganic forms of Se, more bioavailable and have the ability to scavenge ROS directly (Amini and Mahabadi, 2018). In addition, secondary metabolites derived from plants are being used in order to synthesize and stabilize NMs, thereby reducing negative impacts on human health and the environment (Amini, 2019). Based on this approach, Au NPs were synthesized using the natural flavonoid apigenin and later these NPs were used to treat cancer in mice; the results obtained indicate that NPs were efficient to eradicate cancer cells, in addition to being more stable in the environment and are much less toxic than other types of Au NPs (Amini et al., 2021). The use of this type of environmentally friendly technologies and with the potential to decrease the negative impact of NMs definitely increases the possibility of being able to apply various NMs in agriculture.

Although all these positive impacts both on the development of agricultural crops and on the increase of bioactive compounds in the plant organs that we use as food are documented (Lala, 2021; Rivero-Montejo et al., 2021; Rizwan et al., 2017), there is a fundamental question that must be answered before commercial application of these NMs. The benefit of using NMs in agriculture is greater than the possible risks that could be observed in the long term, such as the impact on the environment through food chains or even on human health itself? Obviously, to answer this question, it is necessary to deepen the research on the impacts of NMs not only in plant species, but also in other living organisms. In addition, it is necessary to carry out research on the movement that NMs may have through the different trophic levels, since it has been shown that it is possible (Bergami et al., 2017), in order to determine the extent to which complete ecosystems can be impacted, and not only with partial knowledge. Even more so if we take into account that the use of nanomaterials in other industries such as pharmaceuticals, electrical, cosmetic, food, and others, is constantly growing (Ashraf et al., 2021; Wu et al., 2020), which results in a greater production of NMs to satisfy the demand and consequently a greater release of these to the environment (Pereira et al., 2020; Salieri et al., 2018). Fortunately, progress has been made in regulating the use of NMs, and especially in the methods that allow evaluating the potential risks of these materials in the environment (Petersen et al., 2021). This will definitely favor the potential application of NMs in a safe manner. However, and despite the positive evidence of the use of NMs in agriculture, we should consider the possible negative implications that we cannot perceive for now, but that can definitely impact enormously at any given time on food production through agricultural crops and human health, before the extensive use in agriculture.

Author Contribution: The author confirms sole responsibility for the following: study conception and design, data collection, analysis and interpretation of results, and manuscript preparation. 
Funding Statement: The author received no specific funding for this study.

Conflicts of Interest: The author declares that he has no conflicts of interest to report regarding the present study.

\section{References}

Ahmed S, Gao X, Jahan MA, Adams M, Wu N, Kovinich N (2021). Nanoparticle-based genetic transformation of Cannabis sativa. Journal of Biotechnology 326: 48-51. DOI 10.1016/j. jbiotec.2020.12.014.

Amini SM (2019). Preparation of antimicrobial metallic nanoparticles with bioactive compounds. Materials Science and Engineering C 103: 109809. DOI 10.1016/j.msec.2019.109809.

Amini SM, Gilaki M, Karchani M (2014). Safety of nanotechnology in food industries. Electron Physician 6: 962-968. DOI 10.14661/2014.962-968.

Amini SM, Mahabadi VP (2018). Selenium nanoparticles role in organ systems functionality and disorder. Nanomedicine Research Journal 3: 117-124. DOI 10.22034/NMRJ.2018.03.001.

Amini SM, Mohammadi E, Askarian-Amiri S, Azizi Y, ShakeriZadeh A, Neshastehriz A (2021). Investigating the in vitro photothermal effect of green synthesized apigenin-coated gold nanoparticle on colorectal carcinoma. IET Nanobiotechnology 15: 329-337. DOI 10.1049/nbt2.12016.

Amiri S, Yousefi-Ahmadipour A, Hosseini MJ, Haj-Mirzaian A, Momeny $M$ et al. (2018). Maternal exposure to silver nanoparticles are associated with behavioral abnormalities in adulthood: Role of mitochondria and innate immunity in developmental toxicity. NeuroToxicology 66: 66-77. DOI 10.1016/j.neuro.2018.03.006

Ashraf SA, Siddiqui AJ, Elkhalifa AEO, Khan MI, Patel M et al. (2021). Innovations in nanoscience for the sustainable development of food and agriculture with implications on health and environment. Science of the Total Environment 768: 144990. DOI 10.1016/j.scitotenv.2021.144990.

Awasthi G, Singh T, Tiwari Y, Awasthi A, Tripathi RD et al. (2020). A review on nanotechnological interventions for plant growth and production. Materials Today: Proceedings 31: 685-693. DOI 10.1016/j.matpr.2020.07.255.

Azizi-Lalabadi M, Hashemi H, Feng J, Jafari SM (2020). Carbon nanomaterials against pathogens; the antimicrobial activity of carbon nanotubes, graphene/graphene oxide, fullerenes, and their nanocomposites. Advances in Colloid and Interface Science 284: 102250. DOI 10.1016/j.cis.2020.102250.

Bergami E, Pugnalini S, Vannuccini ML, Manfra L, Faleri C et al. (2017). Long-term toxicity of surface-charged polystyrene nanoplastics to marine planktonic species Dunaliella tertiolecta and Artemia franciscana. Aquatic Toxicology 189: 159-169. DOI 10.1016/j.aquatox.2017.06.008.

Cisternas-Jamet J, Salvatierra-Martínez R, Vega-Gálvez A, Stoll A, Uribe $E$ et al. (2020). Biochemical composition as a function of fruit maturity stage of bell pepper (Capsicum annum) inoculated with Bacillus amyloliquefaciens. Scientia Horticulturae 263: 109107. DOI 10.1016/j.scienta.2019.109107.

Corredor E, Testillano PS, Coronado MJ, González-Melendi P, Fernández-Pacheco R et al. (2009). Nanoparticle penetration and transport in living pumpkin plants: In situ subcellular identification. BMC Plant Biology 9: 1-11. DOI 10.1186/ 1471-2229-9-45.

Cortés-Estrada CE, Gallardo-Velázquez T, Osorio-Revilla G, Castañeda-Pérez E, Meza-Márquez OG et al. (2020).
Prediction of total phenolics, ascorbic acid, antioxidant capacities, and total soluble solids of Capsicum annuum L. (bell pepper) juice by FT-MIR and multivariate analysis. LWT-Food Science and Technology 126: 109285. DOI 10.1016/j.lwt.2020.109285.

Das A, Kamle M, Bharti A, Kumar P (2019). Nanotechnology and it's applications applications in environmental remediation: An overview. Vegetos 32: 227-237. DOI 10.1007/s42535-01900040-5.

He A, Jiang J, Ding J, Sheng GD (2021). Blocking effect of fullerene nanoparticles $\left(\mathrm{nC}_{60}\right)$ on the plant cell structure and its phytotoxicity. Chemosphere 278: 130474. DOI 10.1016/j. chemosphere.2021.130474.

Jordan JT, Singh KP, Cañas-Carrell JE (2018). Carbon-based nanomaterials elicit changes in physiology, gene expression, and epigenetics in exposed plants: A review. Current Opinion in Environmental Science \& Health 6: 29-35. DOI 10.1016/j.coesh.2018.07.007

Juárez-Maldonado A, Ortega-Ortiz H, González-Morales S, MorelosMoreno Á, Cabrera-de la Fuente $\mathrm{M}$ et al. (2019). Nanoparticles and nanomaterials as plant biostimulants. International Journal of Molecular Sciences 20: 1-19. DOI 10.3390/ijms20010162.

Juárez-Maldonado A, Tortella G, Rubilar O, Fincheira P, BenavidesMendoza A (2021). Biostimulation and toxicity: The magnitude of the impact of nanomaterials in microorganisms and plants. Journal of Advanced Research 31: 113-126. DOI 10.1016/j.jare.2020.12.011.

Khodakovskaya MV, de Silva K, Biris AS, Dervishi E, Villagarcia H (2012). Carbon nanotubes induce growth enhancement of tobacco cells. ACS Nano 6: 2128-2135. DOI 10.1021/ nn204643g.

Kumar A, Gupta K, Dixit S, Mishra K, Srivastava S (2019). A review on positive and negative impacts of nanotechnology in agriculture. International Journal of Environmental Science and Technology 16: 2175-2184. DOI 10.1007/s13762-018-2119-7.

Lala S (2021). Nanoparticles as elicitors and harvesters of economically important secondary metabolites in higher plants: A review. IET Nanobiotechnology 15: 28-57. DOI $10.1049 /$ nbt2.12005.

Machado R, Serralheiro R (2017). Soil salinity: Effect on vegetable crop growth. Management practices to prevent and mitigate soil salinization. Horticulturae 3: 1-13. DOI 10.3390/horticulturae3020030.

Marslin G, Sheeba CJ, Franklin G (2017). Nanoparticles alter secondary metabolism in plants via ROS burst. Frontiers in Plant Science 8: 1-8. DOI 10.3389/fpls.2017.00832.

Mittler R (2017). ROS are good. Trends in Plant Science 22: 11-19. DOI 10.1016/j.tplants.2016.08.002.

Moulick RG, Das S, Debnath N, Bandyopadhyay K (2020). Potential use of nanotechnology in sustainable and 'smart' agriculture: Advancements made in the last decade. Plant Biotechnology Reports 14: 505-513. DOI 10.1007/s11816020-00636-3.

Nazir F, Hussain A, Fariduddin Q (2019). Hydrogen peroxide modulate photosynthesis and antioxidant systems in tomato (Solanum lycopersicum L.) plants under copper stress. Chemosphere 230: 544-558. DOI 10.1016/j. chemosphere.2019.05.001.

Pereira AC, Gonçalves BB, Brito Rda S, Vieira LG, Lima ECde O, Rocha TL (2020). Comparative developmental toxicity of iron oxide nanoparticles and ferric chloride to zebrafish (Danio rerio) 
after static and semi-static exposure. Chemosphere 254: 126792. DOI 10.1016/j.chemosphere.2020.126792.

Pérez-de-Luque A (2017). Interaction of nanomaterials with plants: What do we need for real applications in agriculture? Frontiers in Environmental Science 5: 1-7. DOI 10.3389/ fenvs.2017.00012.

Petersen EJ, Goss GG, von der Kammer F, Kennedy AJ (2021). New guidance brings clarity to environmental hazard and behaviour testing of nanomaterials. Nature Nanotechnology 16: 482-483. DOI 10.1038/s41565-021-00889-1.

Petersen EJ, Mortimer M, Burgess RM, Handy R, Hanna $S$ et al. (2019). Strategies for robust and accurate experimental approaches to quantify nanomaterial bioaccumulation across a broad range of organisms. Environmental Science: Nano 6: 1619-1656. DOI 10.1039/C8EN01378K.

Rivero-Montejo Sde J, Vargas-Hernandez M, Torres-Pacheco I (2021). Nanoparticles as novel elicitors to improve bioactive compounds in plants. Agriculture 11: 1-16. DOI 10.3390/agriculture11020134.

Rizwan M, Ali S, Qayyum MF, Ok YS, Adrees M et al. (2017). Effect of metal and metal oxide nanoparticles on growth and physiology of globally important food crops: A critical review. Journal of Hazardous Materials 322: 2-16. DOI 10.1016/j.jhazmat.2016.05.061.

Ruíz-Huerta EA, de la Garza Varela A, Gómez-Bernal JM, Castillo F, Avalos-Borja M et al. (2017). Arsenic contamination in irrigation water, agricultural soil and maize crop from an abandoned smelter site in Matehuala, Mexico. Journal of
Hazardous Materials 339: 330-339. DOI 10.1016/j. jhazmat.2017.06.041.

Salieri B, Turner DA, Nowack B, Hischier R (2018). Life cycle assessment of manufactured nanomaterials: Where are we? NanoImpact 10: 108-120. DOI 10.1016/j.impact.2017.12.003.

Singh RP, Handa R, Manchanda G (2021). Nanoparticles in sustainable agriculture: An emerging opportunity. Journal of Controlled Release 329: 1234-1248. DOI 10.1016/j.jconrel.2020.10.051.

Tripathi DK, Shweta, Singh S, Singh S, Pandey R et al. (2017). An overview on manufactured nanoparticles in plants: Uptake, translocation, accumulation and phytotoxicity. Plant Physiology and Biochemistry 110: 2-12. DOI 10.1016/j.plaphy.2016.07.030.

Wu D, Ma Y, Cao Y, Zhang T (2020). Mitochondrial toxicity of nanomaterials. Science of the Total Environment 702: 134994. DOI 10.1016/j.scitotenv.2019.134994.

Yan S, Zhao L, Li H, Zhang Q, Tan J, Huang M, He S, Li L (2013). Single-walled carbon nanotubes selectively influence maize root tissue development accompanied by the change in the related gene expression. Journal of Hazardous Materials 246-247: 110-118. DOI 10.1016/j.jhazmat.2012.12.013.

Zhou H, Liu J, Dai T, Muriel Mundo JL, Tan Y et al. (2021). The gastrointestinal fate of inorganic and organic nanoparticles in vitamin $\mathrm{D}$-fortified plant-based milks. Food Hydrocolloids 112: 106310. DOI 10.1016/j. foodhyd.2020.106310.

Zulfiqar F, Ashraf M (2021). Nanoparticles potentially mediate salt stress tolerance in plants. Plant Physiology and Biochemistry 160: 257-268. DOI 10.1016/j.plaphy.2021.01.028. 